\title{
A PALEONTOLOGIA NA EDUCAÇÃO INFANTIL: ALFABETIZANDO E CONSTRUINDO O CONHECIMENTO
}

\author{
Palenteology in the kindergarten: \\ teaching and building knowledge
}

\author{
Fernanda Torello de Mello ${ }^{1}$ \\ Luiz Henrique Cruz de $\mathrm{Mello}^{2}$ \\ Maria Beatriz de Freitas Torello ${ }^{3}$
}

\begin{abstract}
Resumo: A Paleontologia é recomendada pelos PCN como tema de ciências para o ensino básico brasileiro, sendo freqüente em muitos livros didáticos no País. Abordagens mais completas sobre o tema são, ainda, escassas no dia-a-dia das escolas, devido mais à deficiência dos professores do que ao desinteresse ou dificuldades de aprendizado dos alunos. São descritas aqui iniciativas de atuação junto à Educação Infantil, envolvendo o colégio, professores e alunos. O que se propõe é usar a Paleontologia na alfabetização e na construção do conhecimento, por meio do contato dos alunos com esse tema desde suas atividades educativas iniciais. Visa à popularização do conhecimento paleontológico, à aproximação entre Universidade-Escola, à formação continuada de professores e à prestação de assessoria na elaboração/execução de atividades. As atividades aqui relatadas, mais do que idéias a serem copiadas, devem servir como idéias geradoras de idéias, sendo adaptadas à realidade e às condiçốes de cada um dos interessados.
\end{abstract}

Palavras-chave: Educação Infantil. paleontologia. divulgação científica.

Abstract: Paleontology is recommended by PCN's (Brazilian Curricular Parameters) as a subject to be developed in basic education. Such theme frequently figures in many text-books all over the country. However, more complete approaches are rarely incorporated into daily teaching practices. Such absence seems to be more related to teachers' personal deficiencies (during their training) than to students' limitations (lack of interest or difficulties in learning process). Here we describe some actions related to kindergarten education working with the school (building), teachers, and children. The main proposal is to use Paleontology in the initial "read and write process", presenting this theme from the very beginning kindergarten activities. Final goals are related to paleontological knowledge becoming more popular in Brazilian basic education, to bring together University and School, to encourage with up to date of teachers' knowledge, and to help educators in setting up and executing activities on Paleontology. The actions mentioned here, more than ideas to be imitated, must work as feedback to generate new ideas, adjustable to particular conditions.

Keywords: kindergarten education. paleontology. scientific diffusion.

\section{Introdução}

Abordagens geológicas e paleontológicas fazem parte do conteúdo de Ciências trabalhado em todos os níveis da educação no Brasil - Ensino Infantil, Fundamental e Médio

\footnotetext{
${ }^{1}$ Professora Doutora, Departamento de Biologia, Centro de Ciências Psicológicas e da Saúde, Universidade Federal de Sergipe (UFS). E-mail: torello.mello@uol.com.br

${ }^{2}$ Professor Doutor, Departamento de Geografia, Centro de Educação e Ciências Humanas, Universidade Federal de Sergipe (UFS).

${ }^{3}$ Pedagoga, assessora pedagógica.
} 
Mello, F. T. et al.

- (MINISTÉRIO DA EDUCAÇÃO E DO DESPORTO, 1998), muito embora os materiais didáticos existentes demandem, na maioria das vezes, revisão e complementações. Em Geologia, o que se observam são informações gerais sobre nosso planeta (p. ex., constituição, forma, distribuição dos continentes, tipos de rochas e minerais) e, mais recentemente, problemas ambientais decorrentes da interação homem-litosfera (p. ex., enchentes, assoreamento). A Paleontologia, por sua vez, é introduzida mormente, por meio dos dinossauros e, apenas esporadicamente, permeia por outros assuntos, como a origem da vida, definiçãao e tipos de fósseis. Essa é uma realidade que atinge alunos até 17 anos.

As informações contidas em materiais paradidáticos são uma boa alternativa de complementação ao conhecimento paleontológico geralmente oferecido, podendo ser utilizadas tanto nas escolas quanto fora delas. Contudo, a produção desse tipo de material pelos paleontólogos brasileiros ainda é tímida, embora alguns exemplos possam ser apontados como iniciativas de reconhecido mérito (ANELLI, 2003; CAMOLEZ e ANELLI, 2003; HENRIQUES et al., 1999; MACHADO et al., 2003).

Os livros didáticos, no entanto, são os materiais que estão mais diretamente ligados aos alunos, certo? Sim, mas não se pode ignorar um elemento fundamental na ligação entre os livros e os alunos: os professores. O que se observa, de uma maneira geral, é uma grande deficiência na formação dos professores quanto aos conteúdos de ciências, incluindo Paleontologia. Para entender isso, deve-se analisar o ambiente universitário. É comum identificar que, geralmente, há maior interesse e dedicação das instituições na formação de pesquisadores do que de professores para atuarem nos diferentes níveis da educação (BARBIERI, 2002). Especificamente, mesmo os cursos de licenciatura plena, que deveriam dar o suporte e a formação necessários para os profissionais, apresentam, ainda hoje, deficiências na transmissão dos conteúdos de ciências (DELIZOICOV e ANGOTTI, 1990). Situação mais grave ainda pode ser facilmente encontrada na Educação Infantil, onde muitos dos professores, formados no extinto curso normal ou mesmo em pedagogia, têm de se dividir entre os conteúdos de Língua Portuguesa, Matemática, Estudos Sociais e Ciências, o que resulta em nítida deficiência de conhecimentos específicos de ciências (DELIZOICOV e ANGOTTI, 1990), incluindo também a Paleontologia.

Diante dessas constatações, a impressão que se tem é de que a Paleontologia é um assunto muito complexo e, como tal, deve ficar restrito aos laboratórios, ambientes hostis, sombrios e empoeirados, na visão de muitos. De fato, não podemos negligenciar a complexidade da Paleontologia, advinda de seu caráter integrador, em que diversos ramos do conhecimento científico (e.g., biologia, geologia, informática, só para citar alguns) interagem para resolver problemas relacionados às formas de vida pretéritas. No entanto, muitos resultados de pesquisas paleontológicas podem ser de interesse geral da população e, portanto, passíveis de serem transmitidos além dos limites da universidade.

O impacto da deficiência desse conteúdo nos livros e materiais didáticos, conforme comentado, poderia ser um pouco amenizado com a condução das crianças aos museus e exposiçōes sobre o tema, fazendo com que elas vivenciassem e assimilassem a grandiosidade e a importância desse ramo das ciências naturais. E não restam dúvidas de que a população aceita bem esse tipo de iniciativa, haja vista o sucesso recente obtido por algumas instituições brasileiras, entre elas as exposições realizadas no Museu Nacional (Rio de Janeiro) (KELLNER, 
2004a, b). No entanto, espaços dessa natureza (museus, salas temáticas, exposições) ainda constituem raridades em muitas cidades brasileiras, o que restringe ainda mais o acesso da população a essa cultura (para exceções, veja Museu de Paleontologia de Monte Alto/SP, de Uberaba/MG, de Belo Horizonte/MG, Museu Nacional do Rio de Janeiro/RJ, Museu de História Natural de Taubaté/SP, entre outros).

Pelo comentado até aqui, três pontos se destacam nesse contexto: a) deficiência de material didático e paradidático; b) deficiência na formação dos alunos e professores/educadores; e c) distanciamento entre Universidade-Sociedade. Esses elementos interagem formando um ciclo e culminando no desinteresse geral pelo tema, sob o mito da complexidade. A deficiência no ensino e nos materiais disponíveis causam distanciamento das crianças em relação à Paleontologia, o que faz com que elas ignorem seus ícones e conceitos mais elementares. Desconhecendo as informações básicas não se cria demanda suficiente para manter museus e exposições, onde a formação escolar poderia ser complementada. Se não há demanda, não há grande interesse dos paleontólogos acadêmicos em gastarem parte do tempo de suas pesquisas com o desenvolvimento de materiais complementares e exposiçōes, ficando a Paleontologia restrita aos laboratórios. Dessa forma, os profissionais que se formam na universidade, e que têm contato com a Paleontologia, são estimulados a desenvolverem pesquisa e atuarem em laboratórios, ao passo que os profissionais que atuarão diretamente com os ensinos infantil, fundamental e médio acabam tendo apenas uma formação paleontológica superficial, e não conseguem despertar o interesse pelo tema em seus alunos. Voltamos, pois, ao início do ciclo.

O quadro exposto até aqui resume a relação da Paleontologia com o ensino de base no Brasil. Deve ser considerado, entretanto, não ser este uma exclusividade dessa área da Ciência, uma vez que tal distanciamento também pode ser notado em diversos ramos das ciências Exatas e Biológicas. É estimulante, contudo, para nós paleontólogos, verificar que tal situação vem sendo identificada há algum tempo por diversos profissionais. Neste contexto, algumas iniciativas anteriores a este projeto puderam ser identificadas e constituem também fontes de dados para educadores, principalmente relacionadas à divulgação, análise e utilização da Paleontologia no ensino fundamental e médio (ARRUDA-CAMPOS, 1997; SILVA, 1997; MATUSIAK e RIBEIRO, 1997; RÖSLER e FRITSCH, 1997; LEAL et al., 1997; BARRETO et al., 1999; SCHWANKE et al., 1999; ZAMPIROLLI et al., 1999; ZUCON, 1999; KELLNER, 2001; MARQUES, 2001a, b; SILVA et al., 2001; MELO et al., 2003). De maneira similar, algumas propostas surgiram após a realização deste projeto, estando relacionadas à divulgação (FERNANDES, 2003, KAZUBEK, 2003; NASCIMENTO et al., 2003), utilização e análise da Paleontologia no ensino (ZUCON, 2003; GONÇALVES e MACHADO, 2003; MOURA e BARRETO, 2003; FERNANDES et al., 2003; FERREIRA et al., 2003; OLIVEIRA et al., 2003; TORELLO et al., 2003; AMADEU e SCHWANKE, 2004; SCHWANKE e SILVA, 2004; SOARES et al., 2004).

\section{Objetivos}

Uma vez identificadas essas carências com relação à Paleontologia, foram traçadas as diretrizes de um projeto com duas frentes principais de atuação, incluindo o contato das crianças com a Paleontologia e a formação continuada de professores da Educação Infantil. 
Mello, F. T. et al.

O objetivo central deste projeto foi utilizar a Paleontologia como ferramenta nas atividades iniciais de aprendizagem de alunos da Educação Infantil. A partir disso, os seguintes objetivos específicos puderam ser traçados:

- promover o contato das crianças com a Paleontologia desde cedo, fazendo com que esse tema seja naturalmente inserido em suas atividades educativas iniciais;

- popularizar o conhecimento paleontológico, tendo a criança como disseminadora do conhecimento adquirido em sala de aula;

- empregar a Paleontologia no processo de alfabetização;

- demonstrar a possibilidade da aproximação Paleontologia-Escola;

- atuar junto aos professores/educadores na forma de um curso de formação continuada;

- prestar assessoria direta aos professores na elaboração e execução de atividades e esclarecimento de dúvidas sobre o tema.

\section{Resultados}

\section{Considerações Teóricas}

Um projeto com essas características e objetivos não pode ficar restrito ao conteúdo dos livros didáticos nem ao conhecimento prévio dos professores sobre o tema. Necessita, portanto, de iniciativas criativas, informativas e, sobretudo, adequadas à faixa etária com a qual se está trabalhando, respeitando-se o desenvolvimento intelectual de cada idade e procurando trabalhar com aquelas informações que as crianças têm, efetivamente, condições de assimilar (veja, por exemplo, os 4 estágios do desenvolvimento cognitivo de Kreitler e Kreitler, 1990). De acordo com Hodson (2003), a experiência mostra que crianças pequenas podem ser estimuladas pela simples manipulação de objetos e observação de fatos, ao passo que para crianças mais velhas é necessário um estímulo cognitivo, explorando idéias e participando de investigações. Não é interessante restringir os conhecimentos que serão transmitidos, mesmo aqueles relacionados a ciências em geral.

No momento em que a criança está em contato com o objeto de investigação, é sabido que sua capacidade de absorção dos conhecimentos é muito grande, porém ainda não se conhecem os efeitos desta assimilação ao longo do tempo, ou seja, se estes conhecimentos permanecem por muito tempo ou não na memória de crianças entre três e seis anos. Assim, é importante que todo e qualquer conhecimento ao alcance das crianças da Educação Infantil, que chame atenção, seja transmitido sem restrições e de maneira clara e lúdica para que estas possam assimilar com facilidade e, por que não, levar este conhecimento por toda sua vida. Desta maneira, algumas iniciativas foram tomadas visando trabalhar o conjunto EscolaProfessor-Aluno.

As atividades aqui apresentadas foram realizadas no ano de 2002, nas dependências do Colégio Pequenópolis (São Paulo, SP), e dirigidas a crianças de quatro a seis anos. Esses alunos da Educação Infantil utilizavam, como material didático principal, as apostilas do Sistema Anglo de Ensino (FONTES e ASSUMPÇÃO, 2002a, b). Uma análise crítica desse material didático destaca seu caráter inovador, sobretudo em dois aspectos: a) na faixa de idade a que se destina e b) por tratar a Paleontologia, grosso modo, de maneira precisa, do ponto de vista científico e com assuntos diversos, muito além dos dinossauros. O material didático 
destinado à Educação Infantil constitui peça fundamental na alfabetização, pois é nessa idade que as crianças iniciam o processo, incluindo leitura e escrita, além da aquisição de conhecimentos adicionais. É fundamental, portanto, que o material utilizado em sala de aula ofereça uma linguagem instigante e o professor seja orientado a auxiliar as crianças a conhecer o mundo ao seu redor, interessar-se por ele, explorá-lo, questioná-lo, raciocinar, descobrir respostas e, assim, construir seu conhecimento (HARLAN e RIVKIN, 2002).

Sobre essa temática, é importante também ressaltar que a forma como é transmitido o conhecimento pode influenciar o aluno durante toda a vida. Nesse ponto, devemos considerar o papel do professor junto aos alunos resultado de seu conhecimento (oriundo da formação e da atualização constante) e comportamento perante a alunos (CURTO et al., 2000). Harlan e Rivkin (2002) enfatizam que, há 30 anos, o conhecido educador para as ciências Glenn Blough já dizia que "... não há registro de crianças inspiradas por professores que não estejam eles mesmos inspirados." Quanto ao conhecimento dos professores, já foram comentadas suas deficiências. Por outro lado, quanto ao comportamento diante dos alunos, as informações dão conta de que a prática mais comum é a de professor como transmissor de conhecimento e não como mediador da construção do conhecimento, como sugere um contexto mais construtivista de atuação (CARRAHER et al., 1985; ROSA, 1994; COLL et al., 1996; HODSON, 2003). A falta de utilização de experiências reais e abordagens diferenciadas do conteúdo de ciências em sala de aula, ultrapassando o limite da utilização do livro didático, está associada diretamente, segundo Harlan e Rivkin (2002), à convicção dos professores da carência de uma bagagem científica para poder responder a todas as perguntas em sala de aula.

Dessa maneira, temos duas frentes que necessitam de atuação e desenvolvimento: aprendizado dos alunos e conhecimento/formação dos professores. Além disso, a metodologia aplicada pela instituição é outro fator decisivo no processo de aprendizagem. Cientes desse quadro, foram elaboradas diversas iniciativas relacionadas à Paleontologia, que pudessem estimular os professores, facilitar o aprendizado dos alunos e tornar mais prazerosa às crianças a realização de suas atividades curriculares cotidianas, aproveitando para desenvolver sua percepção do espaço, do tempo e de como nosso planeta e os organismos se comportaram por meio dele.

\section{Principais iniciativas}

\section{- Alteraçôes no espaço físico do colégio}

Um bom local para as atividades científicas facilita o ato de pensar, funcionando como um convite às crianças para participarem e controlarem as distraçóes. (HARLAN e RIVKIN, 2002)

Com o intuito de auxiliar no processo de alfabetização e construir o conhecimento da criança, tendo a Paleontologia como ferramenta, foram realizadas algumas adaptaçôes no espaço físico preexistente no colégio. As principais mudanças estão descritas a seguir:

Linha do tempo: com 4,5 m de comprimento e 0,9 m de altura, pintada à mão em azulejos brancos, posteriormente queimados em forno de alta temperatura para fixação das cores (Figura 1). Nela, além das indicações sobre os nomes e idades das eras e períodos 
Mello, F. T. et al.

geológicos, podem ser vistos desenhos de organismos representando eventos biológicos de grande destaque na história da vida sobre a Terra (p. ex.: surgimento da vida, dos peixes, do Homem). Desta maneira, a linha do tempo reflete, em escala, a história biológica do planeta.
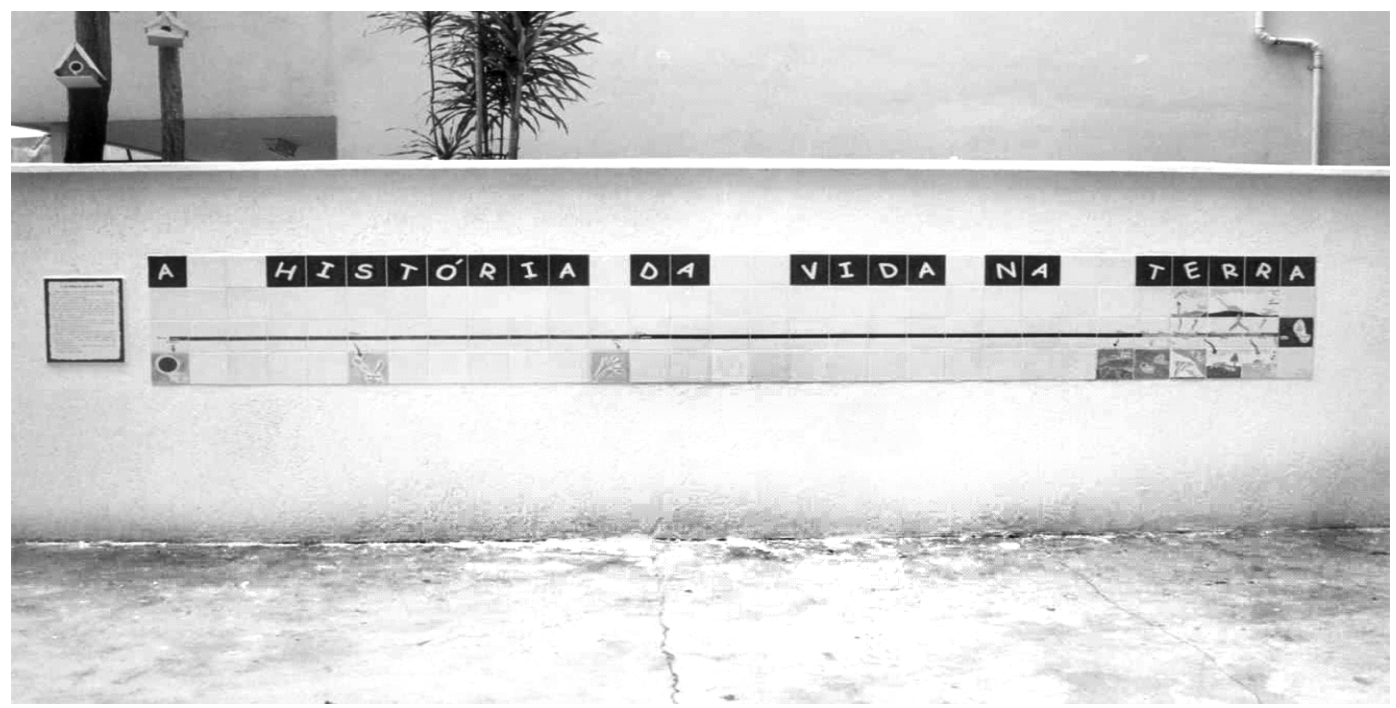

Figura 1: Linha do tempo em azulejos, representando os eventos mais importantes do aparecimento da vida na Terra.

Minijardim paleobotânico: foi desenvolvido sobre um canteiro preexistente, com área de $6 \mathrm{~m}^{2}$. Embora pequeno, os espécimes representantes dos grandes grupos vegetais (p. ex., briófitas, pteridófitas, gimnospermas e angiospermas) foram dispostos respeitando a ordem de surgimento do grupo sobre o planeta, permitindo, assim, visualizar parte da história evolutiva das plantas. Informações adicionais (p. ex.: nome, grupo vegetal, características morfológicas) ficavam disponíveis em placas de identificação, ao lado de cada espécime. Nos casos particulares de algas e cicadáceas, não foi possível a exposição de exemplares, sendo esses grupos representados por placas e ilustrações em seus respectivos lugares dentro da seqüência. Anexo ao minijardim, um espaço coberto foi adaptado para que os professores pudessem realizar atividades, contando com pôsteres permanentes com informações gerais sobre Paleontologia e origem da vida.

Sala de exposiçôes: uma sala de aproximadamente $20 \mathrm{~m}^{2}$ foi destinada à montagem de uma exposição permanente sobre temas paleontológicos. Teve como objetivo principal a complementação dos assuntos vistos em aula, bem como o maior contato dos alunos com a Paleontologia. Para dar suporte a essas atividades, a sala ganhou ares de um pequeno museu (na concepção clássica do termo), transmitindo um clima de mistério e curiosidade, com luzes direcionadas aos fósseis e música ambiente completando o cenário. Parte da sala foi destinada às exposiçôes de fósseis e de réplicas (dos mais variados grupos de organismos), estando associada a uma área para atividades diversas e apresentação de filmes temáticos. Procurou-se organizar a exposição respeitando-se a ordem de aparecimento dos organismos no planeta, sendo que, mesmo quando não era possível expor réplicas de algum grupo, ilustrações e pequenos bonecos permitiam às crianças compreender a seqüência de aparecimento dos organismos. 


\section{- Atividades voltadas ao educador (professores e orientadores educacionais)}

Foi realizado um curso de quatro horas, destinado aos professores e educadores, tendo como objetivo oferecer um complemento ao seu conhecimento prévio, bem como apresentar novos temas paleontológicos. Os vinte participantes puderam acompanhar o desenvolvimento da atividade por meio de uma apostila elaborada com linguagem simples e direta, trazendo informações completas de maneira resumida. Além disso, durante o curso, os educadores foram orientados no desenvolvimento de atividades relacionadas à Paleontologia em sala de aula, analisando de maneira crítica os diversos modos de abordagem desse tema (incluídos no material didático utilizado em sala de aula) e de como trabalhá-los junto aos alunos.

\section{- Canal de dúvidas permanente}

Os professores e educadores que participaram do curso sugeriram a criação de um canal permanente de contato com os paleontólogos participantes desse projeto. Esta iniciativa serviu de suporte permanente às atividades desenvolvidas pelos professores, no que tange ao esclarecimento de dúvidas teóricas sobre os temas abordados nas apostilas, bem como o pedido de material adicional, tanto para aumento do conhecimento do professor quanto para utilização em sala de aula com os alunos. A comunicação podia ser feita todos os dias da semana, durante as 24 horas do dia, por fax e e-mail.

\section{- Atividade de integração paleontólogolaluno}

Uma vez que os alunos começaram a ter contato com os assuntos paleontológicos, os professores viram a necessidade do contato dessas crianças com o "profissional paleontólogo". Foi proposta, então, uma entrevista com dois dos autores do presente artigo, sendo que os alunos atuaram como entrevistadores, elaborando as questões sob orientação dos professores. As questões foram organizadas e previamente enviadas aos entrevistados para que estes pudessem preparar material adicional (p. ex.: fósseis, réplicas, ferramentas). Essa experiência se mostrou válida sob dois pontos de vista principais: a) elucidou algumas questóes relacionadas aos assuntos trabalhados em sala de aula e de interesse individual do aluno; b) permitiu a caracterização do paleontólogo e de sua profissão. Após a entrevista, foi dada aos alunos a chance de demonstrarem seus conhecimentos. Junto à linha do tempo, apresentaram os conhecimentos adquiridos durante as aulas e as atividades desenvolvidas no âmbito do projeto, aproveitando para fazer questionamentos adicionais e espontâneos, conforme os assuntos eram abordados.

\section{- Atividades voltadas às crianças de quatro a 12 anos (férias na escola)}

Em razão do grande interesse demonstrado pelos alunos sobre os temas paleontológicos, como facilmente observado em sala de aula, atividades recreativas de férias foram realizadas em julho de 2002, sendo abertas à comunidade, visando a atrair também as crianças residentes nos arredores da escola. Houve participação de 50 crianças, sendo as atividades diárias, com duração de oito horas e distribuídas em dois finais de semana. As crianças foram agrupadas de acordo com a faixa etária (4-7 anos e 8-12 anos) e cada turma contava com, no máximo, 20 crianças por dia. Cada dia de atividades (Figuras 2 e 3 ) incluía participação em paleogincana, visita monitorada à sala de exposições, apresentação e comentários sobre filmes, trabalhos artísticos (desenhos, pinturas e recortes), escavação, 
Mello, F. T. et al.

confecção de réplicas de fósseis e do sucatassauro (dinossauro com corpo em espuma e ornamentado com sucata), além de caça ao fóssil.

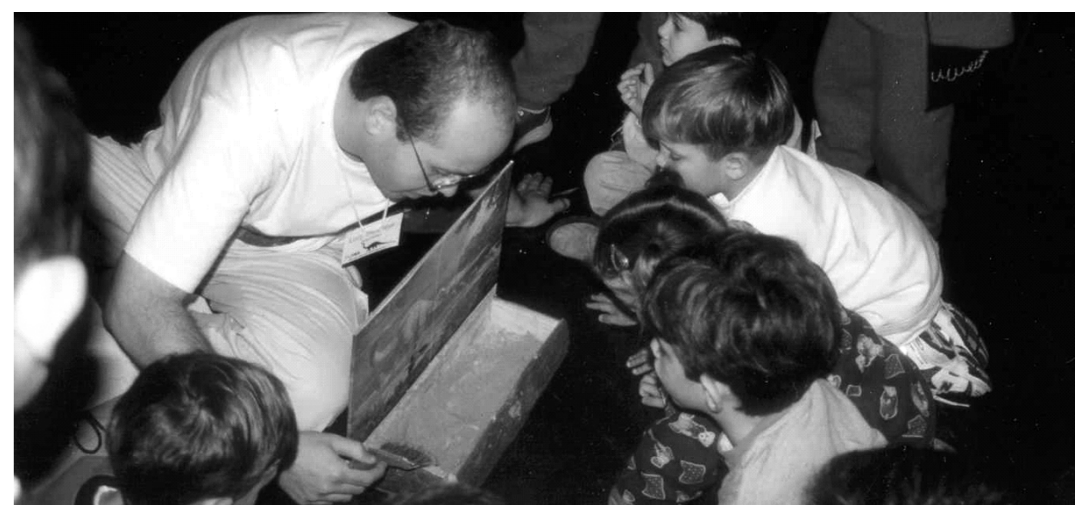

Figura 2: Utilização da caixa de fossilização para demonstração do processo de formação de um fóssil. Atividade realizada durante as "Férias na Escola".

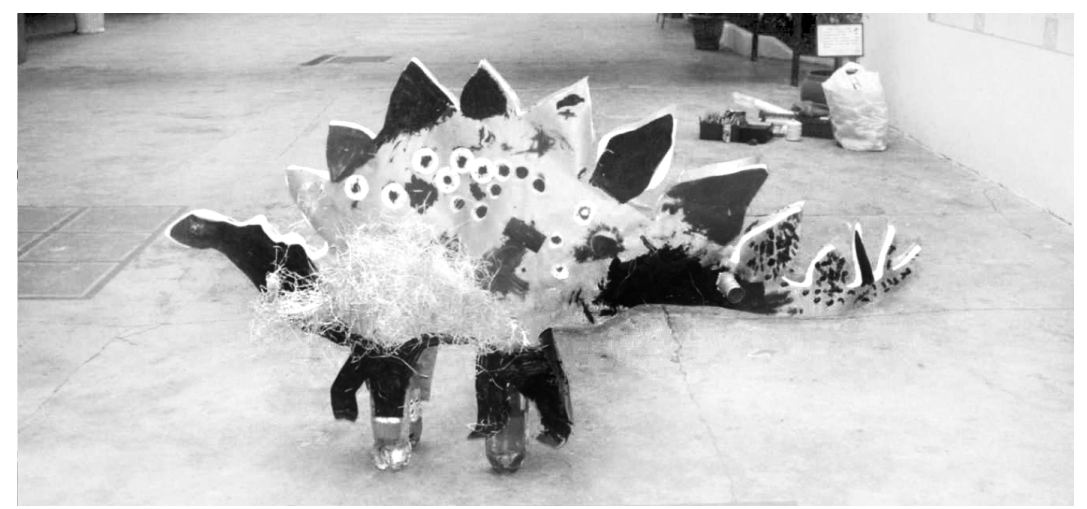

Figura 3: Trabalho artístico de construção do "Sucatassauro", dinossauro confeccionado pelas crianças utilizando diferentes materiais.

\section{Discussão}

As iniciativas relatadas, traduzidas em ações junto a professores, educadores e alunos, ultrapassaram o limite da popularização da Paleontologia, um dos objetivos deste projeto, revestindo-se de uma responsabilidade ainda maior por participarem do início do processo de alfabetização para a maioria das crianças envolvidas. Atualmente, a alfabetização tende a ser ativa e de acordo com o desenvolvimento e interesse de cada criança (FERRERO, 1996). Seguindo essa diretriz, quaisquer temas que preencham esses requisitos podem ser utilizados para dar dinamismo e estimular a alfabetização e o aprendizado, além de ampliar os conhecimentos e as experiências dos alunos, mesmo considerando sua pouca idade. Ferrero (1996) realizou uma série de observaçóes e trabalhos experimentais, que marcaram a transformação do conceito de aprendizagem da escrita pela criança, campo este não estudado por seu mestre e orientador de doutoramento Jean Piaget. Porém, as teorias desenvolvidas por Emilia Ferrero seguem os pressupostos construtivistas/interacionistas de 
Piaget e enfatizam o ato de aprender por meio da construção de um conhecimento realizado pelo aluno, que passa a ser visto não mais como um ser passivo, mas como um agente da construção de seu próprio conhecimento. Entretanto, mesmo que o aluno participe diretamente da construção do conhecimento, a participação do professor é fundamental, organizando atividades que favoreçam a reflexão do estudante sobre a escrita e incentivando seu raciocínio.

Também é importante levar em conta a etapa do desenvolvimento cognitivo, a fim de adequar as atividades propostas ao momento de desenvolvimento, ao longo do qual a criança constrói certas estruturas cognitivas. Para um quadro geral destas etapas do desenvolvimento cognitivo segundo Piaget e adequação das atividades, veja, por exemplo Davis e Oliveira (1990).

E por que não lançar mão da Paleontologia como tema interessante para o estímulo do processo de alfabetização? Seriam as crianças novas demais para lidar com esse tipo de informação? Deveriam as crianças ser poupadas do conhecimento paleontológico básico (p. ex.: o que é paleontologia, o que é um fóssil) e dos termos e nomes científicos corretos, de emprego corriqueiro nessa área? Estes não parecem ser fatores limitantes, uma vez que a complexidade existente em se entender, em linhas gerais, "a formação de um fóssil" e em se pronunciar "Arqueoptherix" nem de longe se compara àquela apresentada pelos desenhos animados da atualidade, conhecidos em todos os seus detalhes pelas crianças. Além disso, a mesma satisfação que uma criança demonstra ao reconhecer as letras de seu nome em palavras simples como "casa" e "bola", ao identificar as letras de seu nome em seu fóssil preferido, seja ele um trilobita ou um pterossauro. Talvez o impedimento esteja mais ligado aos professores, e sua formação defasada e deficiente (HARLAN e RIVKIN, 2002), do que à falta de interesse e dificuldades dos alunos, haja vista o fascínio exercido pelos dinossauros. Obviamente, qualquer que seja a temática abordada, sempre deve haver o acompanhamento de orientadores pedagógicos e a aplicação da metodologia correta, cuja discussão foge dos objetivos do presente trabalho.

Neste trabalho, a Paleontologia foi utilizada como estímulo para a construção do conhecimento e posterior alfabetização dos alunos. As atividades relacionadas à apresentação da Paleontologia às crianças foram realizadas de acordo com as etapas do desenvolvimento cognitivo propostas por Piaget, em que as elas necessitam de atividades direcionadas a pouca idade, uma vez que apresentam pensamento mais concreto e menos lógico. As atividades apontadas aqui e desenvolvidas sob a orientação dos professores e pedagogos foram importantes e obtiveram resultados satisfatórios, pois a experiência com objetos, acontecimentos e espaços exclusivamente preparados a elas (salas de exposição, minijardim paleobotânico, painel com a linha do tempo) levou aos pequenos alunos fundamentos tanto concretos quanto abstratos ao pensamento, concordando com Harlan e Rivkin (2002). Os autores mencionam também que pesquisas posteriores a Piaget demonstram que o pensamento de crianças nessa faixa etária não é tão ilógico assim, e muitas vezes são capazes de raciocinar de modo abstrato, não se limitando ao concreto, podendo variar de indivíduo para indivíduo. Esta observação concorda com os resultados observados durante as atividades descritas aqui, em que principalmente diante da linha do tempo e com a indicação dos principais eventos que ocorreram na Terra, as crianças puderam exercitar pensamentos concretos e, mais tarde, abstratos, porém sempre apoiados em exemplos e materiais palpáveis produzidos ao longo do trabalho, especificamente para este público. 
Mello, F. T. et al.

Desta forma, os resultados obtidos com este projeto podem ser considerados muito positivos tanto para a divulgação da Paleontologia quanto para o desenvolvimento cultural e pedagógico de educadores e alunos. Os aspectos comentados anteriormente, sobre a compatibilidade entre o tema e as crianças/professores, puderam ser analisados a partir do relato de professores e pais de alunos, bem como da observação direta do envolvimento e do desempenho dos professores e alunos nas diferentes atividades. Em termos gerais, as crianças e os professores demonstraram aumento significativo do interesse pelos assuntos abordados, traduzido na forma de freqüentes questionamentos e pelas iniciativas de procurarem e trazerem materiais sobre o tema. Com isso, notamos que, de fato, as crianças na faixa dos quatro aos seis anos podem trabalhar bem com as informações paleontológicas, desde que introduzidas de maneira adequada ao desenvolvimento intelectual de cada faixa etária.

A convivência das crianças com a Paleontologia, no cotidiano do colégio, quer seja por atividades ou pelo contato com os materiais introduzidos (p. ex.: minijardim paleobotânico, sala de exposições), acabou por auxiliar no processo de alfabetização, sendo que elas se sentiram estimuladas e instigadas a entender as palavras e os textos que lhes eram apresentados sobre o tema.

Outro aspecto comentado por pais e professores foi uma evolução na construção do conhecimento. Os alunos, envolvidos pelo tema, levavam para fora da escola os novos conhecimentos adquiridos e, muitas vezes, despertavam nos pais a curiosidade de saber de onde vinham aquelas novas informaçôes, resultando em visitas dos pais, guiadas pelos filhos, às novas instalações do colégio. Nesta etapa, os alunos passaram de meros aprendizes a difusores do conhecimento, discorrendo com muita segurança sobre os assuntos abordados durante as aulas.

Em relação ao desempenho dos professores, nenhuma avaliação formal foi realizada. No entanto, sua formação deficitária, no que tange aos conhecimentos de ciências, ficou evidente ao longo do tempo. Uma análise final, realizada pelos próprios professores, demonstrou que todos se sentiram mais bem preparados e melhor assistidos para a atuação junto aos alunos depois da implantação do projeto. Outro ponto de destaque foi o despertar do interesse dos professores pela Paleontologia, notado sobretudo pelas discussões e questionamentos sobre novas informações divulgadas pela imprensa.

\section{Considerações finais}

Com a execução das ações propostas aqui e os resultados satisfatórios alcançados, fica evidente a exeqüibilidade de projetos dessa natureza no ensino de base, desde a Educação Infantil, como forma de dinamizar a construção do conhecimento e o processo de alfabetização dos alunos. De maneira coordenada, pode-se observar este projeto como uma iniciativa de formação continuada junto aos educadores, reciclando seus conhecimentos e potencializando suas ações perante o material didático empregado ou disponível.

Deve-se considerar, contudo, o custo de execução de um projeto como esse um fator limitante em potencial para muitas escolas, o que prejudicaria a implantação de iniciativas semelhantes, mesmo havendo interesse das escolas sobre o assunto. É evidente que a realização dessas ações, mesmo não tendo sido gastos valores muito altos, contou com o financiamento 
integral do próprio colégio onde foram desenvolvidas. Porém, a falta de recursos financeiros não seria um impedimento para a implantação do projeto, uma vez que alternativas com baixo custo para construção de material são perfeitamente possíveis. Propostas acessíveis de atividades práticas em Paleontologia estão sendo reunidas pelos autores deste artigo e, em breve, serão publicadas. Mais uma vez, deve-se recorrer à criatividade dos professores e ao seu grau de envolvimento com os alunos, conteúdo e aprendizagem, para utilizar as iniciativas descritas neste projeto como pontos de partida para seus desenvolvimentos pedagógicos e didáticos.

Por fim, é importante esclarecer que este artigo apenas relata as experiências desenvolvidas durante a implantação das ações aqui descritas, atuando como exemplos da utilização da Paleontologia no ensino de base, bem como funcionando como diretrizes para aqueles que pretendem desenvolver trabalho semelhante, não necessariamente da mesma maneira, e utilizando os mesmos recursos aqui propostos. A criatividade e a imaginação podem contribuir para driblar a falta de recursos ou mesmo para a implantação de novas propostas diferentes daquelas inicialmente descritas aqui.

\section{Agradecimentos}

Os autores agradecem ao Colégio Pequenópolis (São Paulo-SP), na figura de seu presidente, José Aurélio de Camargo, pela oportunidade e suporte para a realização das atividades. À Maria Célia Montagna de Assumpção (Sistema Anglo de Ensino), pelo incentivo, apoio e valiosas discussões. Aos professores que acolheram esta iniciativa e compreenderam seu valor para o enriquecimento do conhecimento do aluno. À Prof. ${ }^{a}$ Dr. ${ }^{a}$ Renata Guimarães Netto (Unisinos/RS), pela leitura crítica do documento e sugestóes e ao parecerista da revista pelas sugestões e críticas.

\section{Referências}

AMADEU, S. G.; SCHWANKE, C. Textos de mídia no ensino de ciências. In: ENCONTRO "PERSPECTIVAS DO ENSINO DE BIOLOGIA". 2004, São Paulo. Caderno de Programa e Resumos. São Paulo, 2004. p. 88.

ANELLI, L. E. Conhecendo os dinossauros. São Paulo: Ciranda Cultural, 2003.

ARRUDA-CAMPOS, A. C.; BERTINI, R. J. Museu de Paleontologia de Monte Alto: um exemplo de guarda e conservação de materiais fósseis a nível municipal. In: CONGRESSO BRASILEIRO DE PALEONTOlOGIA, 15., 1997, São Pedro. Boletim de Resumos. São Paulo, SBP, 1997. p. 171.

BARBIERI, M. R. Laboratório de Ensino de Ciências. 20 anos de história. Ribeirão Preto: Holos, 2002.

BARRETO, A. M. F. et al. Museu de fósseis Karl Beurlen: um projeto de aplicações educacionais e interações com a sociedade. In: CONGRESSO BRASILEIRO DE PALEONTOlOGIA, 16., 1999, Crato. Boletim de Resumos. Crato, SBP, 1999. p. 24-25. 
Mello, F. T. et al.

BRASIL. Secretaria de Educação Fundamental. Parâmetros Curriculares Nacionais. Brasília: MEC/SEF. Livro 1, 1998.

CAMOLEZ, T.; ANELLI, L. E. Extinção é para sempre. São Paulo: Oficina de Textos, 2003.

CARRAHER, D. W.; CARRAHER, T. N.; SCHLIEMANN, A. D. Caminhos e descaminhos no ensino de ciências. Ciência e Cultura, v. 37, n. 6, p. 889-896, 1985.

COLL, C. et al. O construtivismo na sala de aula. São Paulo: Ática, 1996. Série Fundamentos.

CURTO, L. M.; MORILLO, M. M.; TEIXIDÓ, M. M. Escrever e Ler. v. 1 - Como as crianças aprendem e como o professor pode ensiná-las a escrever e a ler. Porto Alegre: Artmed, 2000.

DELIZOICOV, D; ANGOTTI, J. A. Metodologia do Ensino de Ciências. São Paulo: Cortez, 1990.

FERNANDES, H. D. D.; et al. Museu dos dinossauros e centro de pesquisas paleontológicas Llewellyn Ivor Price: trabalhando a paleontologia a partir de práticas educativas. In: PALEO: PALEONTOLOGIA EM DESTAQUE, 44., 2003. Resumos..., 2003. p. 6.

FERNANDES, C. H. M. et al. Preparação de kits didáticos paleontológicos de exemplares típicos das bacias sedimentares PE-PB e Araripe. In: PALEO: PALEONTOLOGIA EM DESTAQUE, 44., 2003. Resumos..., 2003. p. 6.

FERREIRA, M. F. A. et al. Kit didático (apostila e réplicas de fósseis em gesso) como incentivo à Paleontologia no Ensino Fundamental. In: CONGRESSO BRASILEIRO DE PALEONTOLOGIA, 18., 2003, Brasília. Boletim de Resumos. Brasília, SBP, 2003.

FERRERO, E. Com todas as letras. São Paulo: Cortez, 1996.

FONTES, H. A.; ASSUMPÇÃO, M. C. M. Apostila Educação Infantil, Nivel III: nossas origens. Manual do Professor. Sistema Anglo de Ensino: Gráfica e Editora Anglo, 2002a. 64p.

. Apostila Educação Infantil, Nivel III: nossas origens. Caderno 1. Sistema Anglo de Ensino: Gráfica e Editora Anglo, 2002b, 86p.

GONÇALVES, R. R.; MACHADO, D. M. C. Paleontologia e as histórias em quadrinhos: levantamento de conceitos e termos e utilização como material pedagógico para o ensino fundamental. In: CONGRESSO BRASILEIRO DE PALEONTOLOGIA, 18., 2003, Brasília. Boletim de Resumos. Brasília, SBP, 2003., p.154.

HARLAN, J. D.; RIVKIN, M. S. Ciências na Educação Infantil: uma abordagem integrada. Porto Alegre: Artmed, 2002, 352p.

HENRIQUES, D. D. R.; KELLNER, A. W. A.; SCHWANKE, C. Gonti: uma aventura no tempo dos dinossauros. Rio de Janeiro: Oficinas gráficas da Imprensa da Cidade, 1999. 12p.

HODSON, D. A critical look at practical work in school science. School Science Review, v. 71, n. 256, p. 33-40. 2003. 
A Paleontologia na Educação Infantil: alfabetizando...

KELLNER, A. W. A. Exposição no tempo dos dinossauros. In: CONGRESSO BRASILEIRO DE PALEONTOLOGIA, 17., 2001, Crato. Boletim de Resumos. Crato, SBP, 2001. p. 52-53.

Exposições de Paleontologia. In: ENCONTRO SERGIPANO DE PALEONTOLOGIA, 3., 2004a, Aracaju. Boletim de Resumos. Aracaju, 2004a. p. 17-23.

Museums and paleontological/geological expositions in Brazil. A critique. In: SIMPÓSIO BRASILEIRO DE PALEONTOLOGIA DE VERTEBRADOS, 4., 2004b, Rio Claro. Boletim de Resumos. Rio Claro, 2004b. p. 27-28.

KAZUBEK, M. F. Divulgação da Paleontologia e geologia por meio dos jornais. In: PALEO: PALEONTOLOGIA EM DESTAQUE, 144., 2003. Resumos..., 2003. p. 5.

KREITLER, S.; KREITLER, H. The cognitive foundations of personality traits. Plenum Press, 1990.

LEAL, L. A.; MARTELLO, A. R.; VILLÉN, E. A. Ação educativa para conscientização sobre a importância do acervo paleobotânico e do meio ambiente do Bairro Itararé-Santa Maria-RS. In: CONGRESSO BRASILEIRO DE PALEONTOLOGIA, 15., 1997, São Pedro. Boletim de Resumos. São Pedro, SBP, 1997. p. 179.

MACHADO, V. D.; et al. A importância dos dioramas no ensino de Paleontologia. In: CONGRESSO BRASILEIRO DE PALEONTOLOGIA, 18., 2003, Brasília. Boletim de Resumos. Brasília, SBP, 2003. p. 180.

MARQUES, R. B. A Paleontologia no Ensino Fundamental. In: CONGRESSO BRASILEIRO DE PALEONTOLOGIA, 16., Crato. Boletim de Resumos. Crato, SBP, 2001a. p. 66-67.

Paleontologia no Ensino Médio: projetos. In: CONGRESSO BRASILEIRO DE PALEONTOLOGIA, 16., Crato. Boletim de Resumos. Crato, SBP, 2001b. p. 67-68.

MATUSIAK, M. A.; RIBEIRO, A. M. Kit de Paleontologia: uma proposta referente ao ensino e à divulgação de fósseis brasileiros. In: CONGRESSO BRASILEIRO DE PALEONTOLOGIA, 15., 1997, São Pedro. Boletim de Resumos. São Pedro, SBP, 1997, p. 181.

MELO, M. S. et al. Projeto "Fósseis na escola"- levando a paleontologia ao Ensino Básico no Rio de Janeiro/RJ. In: CONGRESSO BRASILEIRO DE PALEONTOLOGIA, 18., 2003, Brasília. Boletim de Resumos. Brasília, SBP, 2003. p. 193.

MOURA, G. J. B.; BARRETO, A. M. F. Análise do grau de abordagem do tema paleontologia nos livros de biologia do Ensino Médio. In: PALEO: PALEONTOLOGIA EM DESTAQUE, 44., 2003. Resumos..., 2003. p. 5.

NASCIMENTO, S. et al. Exposição itinerante de Paleontologia do Vale do Rio Gravataí. In: CONGRESSO BRASILEIRO DE PALEONTOLOGIA, 18., 2003, Brasília. Boletim de Resumos. Brasília, SBP, 2003. p. 208.

OLIVEIRA, E. C. et al. A aplicação da paleontologia como ciência no Ensino Fundamental. In: PALEO: PALEONTOLOGIA EM DESTAQUE, 44., 2003. Resumos..., 2003. p. 3-4. 
Mello, F. T. et al.

ROSA, S. S. Construtivismo e mudança. Coleção Questôes da nossa época. 2. ed. São Paulo: Cortez Editora, 1994.

RÖSLER, O.; FRITSCH, M. O Centro Paleontológico da UNC-Mafra: um novo centro de pesquisa e museu. In: CONGRESSO BRASILEIRO DE PALEONTOLOGIA, 15., 1997, São Pedro. Boletim de Resumos. São Pedro, SBP, 1997. p. 169.

SCHWANKE, C.; SILVA, M. A. J. Brincando de paleontólogo: levando paleontologia às séries iniciais. In: ENCONTRO "PERSPECTIVAS DO ENSINO DE BIOLOGIA", 2004, São Paulo. Caderno de Programa e Resumos. São Paulo, 2004. p. 23.

- et al. Reconstituição, moldagem, confecção de réplicas e exposição de fósseis: uma atividade integrativa. In: PALEO: CONGRESSO BRASILEIRO DE PALEONTOLOGIA, 16., Boletim de Resumos. Crato, SBP, 1999. p. 99.

SILVA, R. M. et al. Sala das ciências da terra "Prof. Setembrino Petri". Uma contribuição a difusão da paleontologia no Brasil. In: CONGRESSO BRASILEIRO DE PALEONTOLOGIA, 17., 2001, Rio Branco. Boletim de Resumos. Rio Branco, SBP, 2001. p. 183.

SILVA, S. D. A paleontologia nos livros didáticos de $1^{\circ}$ grau: um estudo qualitativo. In: CONGRESSO BRASILEIRO DE PALEONTOLOGIA, 15., 1999, São Pedro. Boletim de Resumos. São Pedro, SBP, 1997. p. 177.

SOARES, S. P.; CAMPOS, L. M. L.; SIMÕES, M. G. Formação continuada em Paleontologia para professores do Ensino Fundamental e Médio: análise de uma proposta. In: ENCONTRO "PERSPECTIVAS DO ENSINO DE BIOLOGIA", 2004, São Paulo. Caderno de Programa e Resumos. São Paulo, 2004. p. 48.

ZAMPIROLLI, A. P. et al. Um jardim paleobotânico, como veículo de compreensão da história evolutiva vegetal destinada à Educação Ambiental. In: PALEO: CONGRESSO BRASILEIRO DE PALEONTOlOGIA, 16., Crato. Boletim de Resumos. Crato, SBP, 1999. p. 128.

ZUCON, M.H. O ensino formal e as práticas educativas de Paleontologia na Universidade Federal de Sergipe. In: PALEO: CONGRESSO BRASILEIRO DE PALEONTOLOGIA, 16., Crato. Boletim de Resumos. Crato, SBP, 1999. p. 129.

- et al. Análise dos conteúdos de paleontologia abordados pelos livros didáticos do Ensino Fundamental. In: CONGRESSO BRASILEIRO DE PALEONTOLOGIA, 18., 2003, Brasília. Boletim de Resumos. Brasília, SBP, 2003. p. 317.

Este projeto foi desenvolvido no ano de 2002, quando o Colégio Pequenópolis adotava o material didático do Sistema Anglo de Ensino e dispunha, em seu quadro de funcionários, de orientadores pedagógicos direcionados especialmente à Educação Infantil. Infelizmente, hoje o método foi abandonado e as iniciativas propostas aqui não foram levadas a diante. Nenhum dos autores possui qualquer vínculo atual com a instituição.

Artigo recebido em abril de 2005 e selecionado para publicação em outubro de 2005. 